\title{
INFECÇOES HOSPITALARES: RETROSPECTIVA E ENFOQUE ATUAL
}

Edna Apparecida Moura Arcuri*

ARCURI, E. A. M. - Infecções Hospitalares: retrospectiva e enfoque atual. Rev. Esc. Enf. USP, 10(3):349-354, 1976.

$O$ autor apresenta uma rápida revisão dos principais fatos ligados ao problema de infeç̧ões hospitalares. Aborda alguns aspectos do assunto controvérsia existente em relação a ele.

Um dos assuntos que muito tem preocupado as autoridades médico-sanitárias de todo o mundo é o das infecções hospitalares.

Infecção é a entrada e proliferação de microrganismos no corpo do homem, animal cu planta. Quando se manifesta durante a hospitalização, ela é chamada de infeç̧ão hospitalar.

Já na antiguidade gregos e romanos usavam aromas como meio de higienização do ambiente. Hipócrates reconheceu a importância de fazer irrigação nas feridas com água fervida. O "Fogo de Londres", após a epidemia de Praga, em 1665, provou ser um meio de desinfecção através da incineração dos ninhos de ratos.

No século passado os pacientes que se submetiam a cirurgia desenvolviam infecção pós-operatória. A ciência da Microbiologia nascia diante do desafio que os microrganismos apresentavam ao homem.

Em 1850, o médico húngaro Semmelweiss associou infecções puerperais à contaminação das mãos dos cirurgiōes e introduziu o hipoclorito de sódio na desinfecção das mãos dos seus estudantes (CAR-

* Auxiliar de ensino da disciplina Fundamentos de Enfermagem da EEUSP. 
TLEDGE, 1975; KURTZ, 1976). Em 1854, durante a guerra da Criméia, Florence Nightingale demonstrou o valor da limpeza das enfermarias. Pasteur, em 1861, provou que a putrefação é um processo fermentativo causado pela proliferação de bactérias. Em 1867, Lister publicou o primeiro artigo sobre princípios de assepsia na prática cirúrgica, no British Medical Journal.

No final do século passado e início deste, surgiram os primeiros trabalhos sobre a ação dos desinfetantes.

Com a descoberta da penicilina, em 1929, por Fleming, novas perspectivas se abriram diante da esperança de resolução completa do problema de infecção. Em 1940, a penicilina foi introduzida efetivamente como o primeiro antibiótico a ser usado na estafilococcias. Nessa época o estafilococo era responsável por sérias epidemias de infecções de pele, terçóis, conjuntivites e furúnculos, além de infecções pulmonares, urinárias e cirúrgicas. As infecções atingiam não só os pacientes como também o pessoal de enfermagem.

No final da década de 40 e início da de 50 , os estafilococos começaram a resistir à ação dos antibióticos. Em 1954 foi isolado um novo tipo de Staphylococcus aureus, que provocou um grande número de infecções superficiais de pele em enfermeiras e algumas infecções fatais em recém-nascidos. Esses fagotipos (80-81) demonstraram ser resistentes à penicilina, estreptomicina e tetraciclina (LACEY, 1976). Entretanto, nas últimas décadas, a antibioticoterapia tem sido usada não só como forma de tratamento mas muitas vezes preventivamente.

Paralelamente às infecções causadas por cocos Gram positivos, tem sido observado especialmente na década de 60 até os dias atuais que grande parte das infecções nosocomiais vem sendo causadas por bacilos Gram negativos, principalmente por enterobactérias como Klebisiella, Enterobacter, Proteus e por Pseudomonas (Mc NAMARA, 1967; ROSENBLATT, 1969: ADLER, 1971; HUTZLER, 1973; MATSEN, 1974; THOBURN, 1974; LACEY, 1976).

Enquanto que alguns trabalhos chamam a atenção para infecçōes causadas por leveduras como a Cândida albicans (WILLIANS, 1970; PETERSON, 1973; KNIGHT, 1975), outros falam de infecções 
causadas por cocos que, até há poucos anos, eram consideradas de pouca importância, como é o caso das infecções urinárias causadas por micrococos resistentes a certos antibióticos (SELLIN et al, 1975).

$\mathrm{O}$ alto custo dos leitos, a resistência bacteriana e o aparente aumento na incidência das infecções nosocomiais levaram as autoridades médico-sanitárias a concentrarem seus esforços no sentido de tentar reduzir o número de infecções.

Já em princípios de 60 foi sugerido que cada hospital tivesse um grupo que se dedicasse ao estudo do problema das infecções, sobretudo em relação à incidência, germes causadores, fontes e controle. Centenas de trabalhos foram publicados, muitos procedimentos sugeridos, normas estipuladas, mas as infecções continuam a trazer problemas ainda hoje.

Embora alguns aspectos do controle das infecções levantem controvérsias, alguns fatos apresentam-se claros, como os fatores que predispõem os pacientes a adquirir infecção, a saber:

- sistema imunitário não completamente desenvolvido, como na caso dos prematuros e recém-nascidos;

- terapia imunossupressora;

- idade avançada;

- debilidade ou estresses físicos;

- hospitalização prolongada com contínua agressão microbiana;

- lesões no tegumento, como queimaduras, problemas dermatológicos e feridas cirúrgicas;

- radiações.

Acredita-se que os microrganismos que têm seu habitat em algumas partes do corpo, como no intestino, e são inofensivos em condições normais podem provocar infecções até fatais quando o paciente tem a sua resistência diminuída por algum dos fatores descritos acima. Quando a infecção é causada por germes que habitam normalmente o organismo, é considerada infecção de causa endógena; quando é adq'irida através de material externo, humano ou inanimado (como sondas, 
cateteres, drenos e outros), diz-se então que é exógena. Atualmente fala-se muito da contaminação de alimentos, desinfetantes e medicamentos, como xaropes, colírios, etc.

Autores têm enfatizado a importância do controle do ambiente no combate às infecções. Alguns, como Litsky, defendem a idéia de que só se pode estar seguro da verdadeira condição do ambiente pela análise de amostras rotineiras. Esse aspecto do problema tem suscitado controvérsias muito bem citadas em recente artigo de DORAN (1975).

O Boletim Epidemiológico (SESP), de 1975, em artigo sobre infeç̧ōes nosocomiais, tendo como base Eichhoff, faz comentários sobre o alto custo das medidas de controle e vigilância do ambiente, colocando de forma questionável o resultado de tais medidas. $\mathrm{O}$ referido boletim faz referências a atitudes divergentes em dois grandes encontros mundiais sobre o assunto, em 1970 e 1972 . Ao passo que em um foi sustentada a idéia de que o problema não era de falta de conhecimentos mas sim da forma como eram comunicados ao pessoal hospitalar, o outro encontro enfatizou a importância de novas descobertas sobre os mecanismos de defesa do hospedeiro e imunossupressores.

O boletim enfatiza também a necessidade de maior número de pesquisas e estudos de áreas que poderiam conduzir a informações clínicas e epidemiológicas úteis, como por exemplo:

- organização de sistemas rápidos e eficientes de diagnóstico para detectar contaminação do ambiente;

- aperfeiçoamento de técnicas diagnósticas e terapêuticas para os pacientes de alto risco;

- maior conhecimiento sobre a fonte exógena ou endógena dos patógenos oportunistas;

- possibilidade de produzir reação de imunidade cruzada por meio de antígenos fracionados, citando a vacina anti-pseudomonas;

- avaliação epidemiológica crítica mais detalhada para definir o risco associado a determinadas doenças e procedimentos, a fim de melhorar a avaliação da exposição desnecessária do paciente a fatores de riscos significativos; 
- estimativas de custos e eficácia das técnicas e dos métodos de controle das infecções hospitalares.

Como última sugestão o boletim ressalta a importância de encorajar abordagens renovadoras mais eficazes de comunicação, que poderiam ser um dos objetivos das comissões de infecção hospitalar. Acreditando que a educação do pessoal hospitalar é ainda um problema básico em nosso meio, chamamos a atenção dos enfermeiros para que colaborem com as comissões de infecção, utilizando-se de abordagens mais eficazes na aplicação dos princípios de assepsia-médico-cirúrgica pela equipe hospitalar.

ARCURI, E. A. M. - Hospital infections: retrospective and present point of view. Rev. Esc. Enf. USP, 10(3):349-354, 1976.

The author presents a revision of the main facts linked to the infection problem. It reports several approaches of the subject and the present controversy.

\section{REFERENCIAS BIBLIOGRAFICAS}

1. ADLER, J. L. et al - Proteus infections in a general hospital. Biochemical characteristics and antibiotic susceptibility of the organisms. Ann. intern. Med., 75 (4): 517, out. 1971.

2. AYLIFFE, G. A. J. et al - Varieties of aseptic practice in hospital wards, Lancet, 2: 1117-20, 22 nov. 1969.

3. CARTLEDGE, K. W. - An introduction to desinfection. Nurs. Times, 71 (37): 1460-61, sep. 11, 1975.

4. DORAN, B. - The infection control controversy. Mod. Healthcare, 4 (3): 46, sep. 1975.

5. GREENE, N. W. - Microbiological contamination control in hospitals. Hospitals, 43: 78-87, out. 1969.

6. HUTZLER, R. U. - Fatores predisponentes de infecção hospitalar. Rev. Hosp. Clin. Fac. Med. S. Paulo, 28(3): 147-152, 1973. 
7. KNIGHT, A. G. - Candidiasis. Nurs. Times, 71(40): 1579-81, oct. 1975.

8. LACEY, R. W. - Changes in Staphylococcal infections and new anti-Staphylococcal antibiotics. Nurs. Times, 72(5): 327-9, 4 mar, 1976.

9. LITSKY, B. Y. - Microbiology and postoperative infections. AORN J., 19(1): 37, jan. 1974.

10. MATSEN, J. M. - Pathogens, their sources and control. Hospitals, 48(23): 71-6, 1 dec. 1974.

11. Mc NAMARA, M. J. et al. - A study of the bacteriology patterns of Hospital Infections. Ann. inter. Med., 66(3): 480, mar. 1967.

12. PETERSON, A. F. - The complex problem of cron infection. AORN J., 17(1): 79-85, jan. 1973.

13. SELLIN, M. et al. - Micro coccal urinary - tract infections in young women. Lancet, 2: 570-2, 27 Dec. 1975.

14. SESP - Infecções Nosocomiais. Boletim epidemiológico, 7(15): 133140, 1975.

15. THOBURN, R. et al. - Infections acquired by hospitalized patients. Arch. Intern. Med., 121(1): 1-10, jan. 1968.

16. WILliaMS, R. J. et al. - Candid Septicemia. Arch. Surg., 103(1): 8-11, jul. 1971. 